BioLink, Vol. 5 (1) Agustus (2018) p-ISSN: 2356- 458X e-ISSN: 2550-1305

DOI: http://dx.doi.org/10.31289/biolink.v5i1.1691

BioLink

Jurnal Biologi Lingkungan, Industri, Kesehatan

Available online http://ojs.uma.ac.id/index.php/biolink

\title{
KEANEKARAGAMAN NEPENTHES DI KECAMATAN SIPIROK
}

\section{Diversity of Nepenthes in Sipirok District}

\author{
Nurmaini Ginting* \\ *Program Studi Pendidikan Biologi Universitas Muhammadiyah Tapanuli Selatan
}

*Corresponding author: E-mail: nurmaini.ginting@um-tapsel.ac.id

\begin{abstract}
Abstrak
Penelitian ini bertujuan untuk mengetahui keanekaragaman jenis Nepenthes di kecamatan Sipirok. Penentuan lokasi penelitian menggunakan metode survey. Pengumpulan data-data tersebut dilakukan dengan menggunakan metode eksplorasi. Ditemukan 7 jenis Nepenthes yaitu Nepenthes eustachya, Nepenthes gracilis, Nepenthes ovata, Nepenthes reinwardtiana, Nepenthes rhombicaulis, Nepenthes tobaica dan satu silangan alami Nepenthes reinwardtiana x Nepenthes tobaica. Nepenthes yang ditemukan merupakan jenis dataran rendah dan dataran tinggi. Ditemukan Nepenthes eustachya pada ketinggian 1008 mdpl, dimana jenis ini sebelumnya hanya ditemukan pada dataran rendah di Sumatera.
\end{abstract}

Kata Kunci: Keanekaragaman, Nepenthes, Kecamatan Sipirok

\begin{abstract}
This research aims to determine the diversity of Nepenthes species in Sipirok sub-district. Location determination research using survey method. The collection of the data is performed using the methods of exploration. Found 7 types of Nepenthes eustachya Nepenthes i.e., Nepenthes ovata, Nepenthes gracilis, Nepenthes rhombicaulis, Nepenthes reinwardtiana, Nepenthes tobaica and Nepenthes reinwardtiana natural silangan one $x$ Nepenthes tobaica. Nepenthes found the lowlands and the Highlands. Nepenthes eustachya is found at an altitude of $1008 \mathrm{mdpl}$, where this type previously found only in lowland Sumatra.
\end{abstract}

Keywords: Diversity, Nepenthes, subdistrict of Sipirok

How to Cite: Ginting, N, (2018), Keanekaragaman Nepenthes di Kecamatan Sipirok, BioLink. Vol.5 (1): Hal. 22-30 
Nurmaini Ginting, Keanekaragaman Nepenthes di Kecamatan Sipirok

PENDAHULUAN

Indonesia merupakan salah satu negara yang memiliki keanekaragaman hayati yang tertinggi di dunia, baik keanekaragaman tumbuhan maupun hewan. Salah satu tumbuhan yang memiliki jumlah jenis tertinggi di Indonesia adalah keluarga Nepenthaceae.

Nepenthes merupakan tumbuhan unik. Variasi bentuk kantung dan warnanya merupakan ciri khas dari anggota famili ini. Kantung berasal dari diferensiasi daun yang digunakan untuk menghasilkan sumber zat hara bagi tumbuhan ini.

Terdapat lebih kurang 200 jenis Nepenthes yang telah teridentifikasi. Lebih dari separuhnya telah ditemukan di Pulau Sumatera dan Kalimantan. Nepenthes tersebar mulai dari pinggiran pantai sampai puncak gunung. Namun, maraknya pembalakan menyebabkan jenis ini menjadi semakin langka (Suprayandi 2007).

Trend tanaman hias juga menjadi salah satu ancaman terhadap anggota kelompok ini. Karena Nepenthes yang diperjual belikan masih merupakan tanaman hasil cabutan dari alam (Fatahul, et al., 2006).

Kecamatan Sipirok merupakn salah satu Kecamatan dari Kabupaten Tapanali Selatan yang terdiri dari dataran tinggi dan diapit oleh beberapa Gunung. Dari hasil penelitian Ginting dan Lubis (2017) Tapanuli Selatan sendiri merupakan salah satu wilayah yang terluas di Sumatera Utara. Daerahnya terdiri dari tepi pantai dan daerah perbukitan yang sangat sesuai untuk pertumbuhan Nepenthes.

\section{METODE PENELITIAN}

Penentuan lokasi penelitian menggunakan metode survey. Pengumpulan data-data tersebut dilakukan dengan menggunakan metode eksplorasi. Dilakukan pencatatan terhadap ciri morfologi pada semua jenis Nepenthes yang ditemukan.

\section{HASIL DAN PEMBAHASAN}

Lokasi penelitian merupakan daerah sekitar pemukiman penduduk, kebun, perbukitan dan gunung. Jenis yang dijumpai merupakan jenis dataran tinggi dan jenis dataran rendah.

Ditemukan 4 jenis merupakan jenis intermediate dimana salah satunya merupakan silangan alami. Dikatakan jenis intermediate karena jenis ini ditemukan pada dataran rendah dan dataran tinggi seperti Nepenthes tobaica, N. Nepenthes reinwardtiana, Nepenthes gracilis dan Nepenthes tobaica $\mathrm{x}$ Nepenthes reinwardtiana. Clarke (2001) menyatakan bahwa populasi yang merupakan jenis intermediat dengan penyebaran mulai dari dataran rendah sampai ketinggian di 
atas $1000 \mathrm{mdpl}$ antara lain Nepenthes Ginting dan Lubis (2017) disebutkan reinwardtiana dan Nepenthes tobaica. bahwa terdapat 11 jenis Nepenthes yang

Secara keseluruhan ditemukan 7 ditemukan di Tapanuli Selatan. Hal ini jenis dari 11 jenis yang telah ditemukan di menunjukkan bahwa Kecamatan Sipirok Kabupaten Tapanuli selatan sesuai dengan memiliki jumlah jenis yang tinggi.

Tabel 1. Jenis-jenis Nepenthes di Kecamatan Sipirok

\begin{tabular}{|c|c|c|c|}
\hline \multirow{2}{*}{ No } & \multirow{2}{*}{ Nama Jenis } & \multicolumn{2}{|c|}{ Ketinggian (mdpl) } \\
\hline & & $0-1000$ & $1001-2200$ \\
\hline 1. & Nepenthes eustachya & - & $\mathrm{V}$ \\
\hline 2. & Nepenthes gracilis & $\mathrm{V}$ & - \\
\hline 3. & Nepenthes ovata & - & $\mathrm{V}$ \\
\hline 4. & Nepenthes reinwardtiana & $\mathrm{V}$ & $\mathrm{V}$ \\
\hline 5. & Nepenthes rhombicaulis & - & $\mathrm{V}$ \\
\hline 6. & Nepenthes tobaica & $\mathrm{V}$ & - \\
\hline 7. & $\begin{array}{l}\text { Nepenthes tobaica } x \text { Nepenthes } \\
\text { reinwardtiana }\end{array}$ & 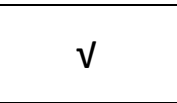 & - \\
\hline & Jumlah & 4 & 4 \\
\hline
\end{tabular}

Pada tabel 1 dapat kita lihat Karakterisasi Morfologi

ditemukan jenis Nepenthes eustachya.

Nepenthes merupakan tumbuhan Jenis ini biasanya hanya ditemukan di yang memiliki ciri meroset ketika masih dataran rendah, namun jenis ini dijumpai pada ketinggian $1008 \mathrm{mdpl}$.

Jenis Nepenthes dataran tinggi yang hanya ditemukan pada ketinggian di atas 2.000 hanya jenis Nepenthes ovata. Sedangkan Nepenthes rhombicaulis tumbuhan muda dan akan menjadi tumbuhan memanjat ketika semakin dewasa. Habit dari tumbuhan biasanya merupakan teresterial, namun beberapa jenis ditemukan epifit.

ditemukan diketinggian 1.800-2.000 mdpl.

Setiap jenis memiliki perbedaan

Jenis Nepenthes yang ditemukan di morfologi, baik bentuk daun, bentuk batang, bunga dan kantung. Perbedaan dataran tinggi memiliki jumlah dan penyebaran yang sangat sedikit. Clarke (1997) menyebutkan bahwa Nepenthes di dataran tinggi memiliki daerah yang paling mencolok ditemukan pada kantungnya.

\section{Batang}

penyebaran yang sangat sempit. meroset dan akan memanjatkan ketika Sebaliknya, jenis Nepenthes dataran dewasa. Tinggi tumbuhan dari 10 - 250 rendah memiliki daerah penyebaran yang $\mathrm{cm}$. Nepenthes yang ditemukan umumnya luas.

memiliki bentuk batang bulat dan licin. Tetapi ada beberapa jenis yang memiliki 
Nurmaini Ginting, Keanekaragaman Nepenthes di Kecamatan Sipirok

batang persegi yang menjadi ciri dari jenis tersebut seperti Nepenthes reinwardtiana dan Nepenthes rhombicaulis. Warna batang bervariasi mulai dari yang berwarna hijau ungu kehitaman, coklat, coklat kehijauan, dan hijau kekuningan.

\section{Daun}

Nepenthes yang ditemukan umumnya memiliki daun yang berbentuk lanset dan seperti spatula, serta tidak memiliki tangkai daun. Hernawati \& Akhriadi (2006) menambahkan bahwa bentuk daun Nepenthes bervariasi mulai dari lanset, oblong, bulat telur terbalik sampai seperti spatula dengan ukuran yang berbeda tergantung jenis dan habitat hidupnya. Clarke (2001) menambahkan bahwa jenisjenis Nepenthes di Sumatera umumnya tidak memiliki tangkai daun.

Tepi daun pada Nepenthes yang dijumpai bervariasi, umumnya rata, tetapi pada beberapa jenis ada yang berbulu (Nepenthes rhombicaulis dan Nepenthes ovata) dan bergerigi (Nepenthes mirabilis).

Semua Nepenthes memiliki tendril (sulur) yang merupakan perpanjangan dari ibu tulang daun bagian apex. Panjang sulur ini bervariasi, tergantung jenis dan umur dari Nepenthes itu sendiri. Pada beberapa jenis sulur ini ditutupi oleh bulubulu halus seperti pada jenis Nepenthes rhombicaulis dan Nepenthes ovata. Hernawati \& Akhriadi (2006) mengatakan

bahwa panjang sulur

bervariasi tergantung pada umurnya.

\section{Kantung}

Kantung merupakan karakter utama dalam identifikasi Nepenthes. Variasi kantung tidak hanya ditemukan pada jenis yang berbeda, tetapi ditemukan juga dalam satu jenis. Bentuk kantung pada saat tumbuhan meroset dan ketika sudah dewasa berbeda. Ditemukan juga kantung intermediet yang merupakan peralihan dari kantung bawah ke kantung atas.

Pada kantung terdapat juga peristome yang menjadi salah satu ciri khas dari kantung Nepenthes. Pada N. ovata peristome lebar dan terlihat jelas. Terdapat juga gigi yang panjang pada peristome. Nepenthes lain yang memiliki peristome lebar seperti N. rhombicaulis, namun giginya kurang jelas. Jenis Nepenthes reinwardtiana, Nepenthes gracilis, Nepenthes tobaica, Nepenthes eustachya dan Nepenthes tobaica $x$ Nepenthes reidwartiana memiliki peristome yang tipis dan gigi tidak jelas. Namun pada Nepenthes eustachya dan Nepenthes tobaica $x \quad$ Nepenthes reinwardtiana peristomenya memiliki corak bergaris berwarna hijau dan merah kehitaman. 

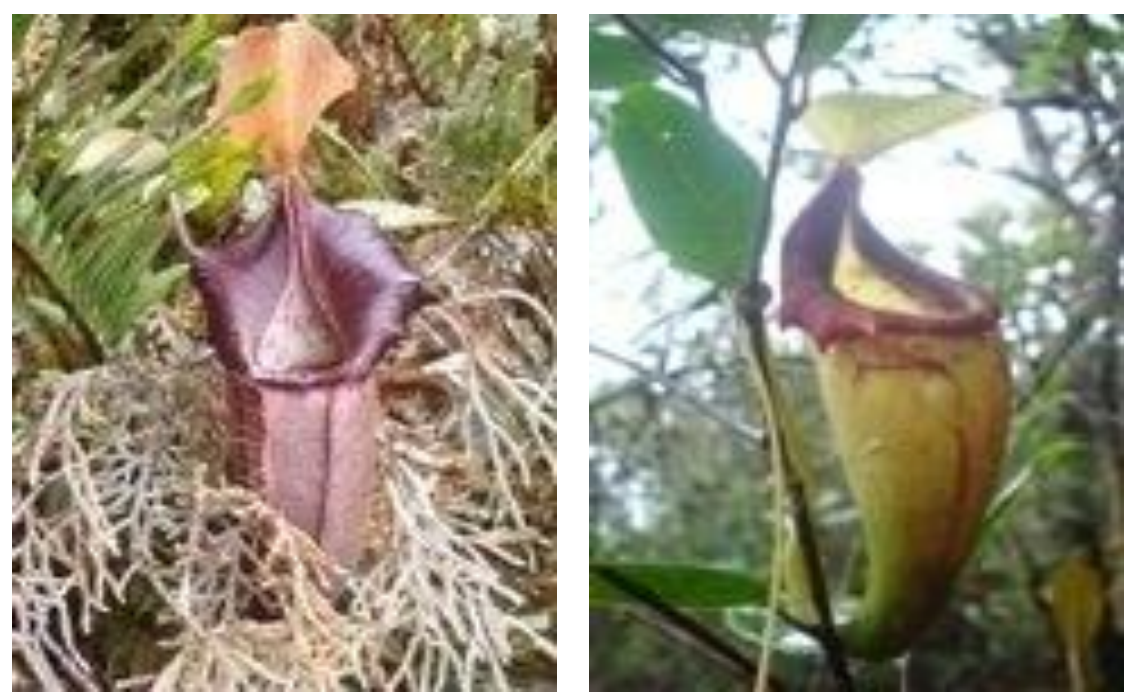

Gambar 1. Bentuk kantung atas dan kantung bawah pada Nepenthes ovata (a) Kantung bawah berbentuk gelas tambun, (b) Kantung atas berbentuk terompet

Kantung bawah umumnya memiliki Perkembangbiakan

Nepenthes

bentuk seperti gentong, sedangkan kantung atas memiliki bentuk seperti kendi. Namun pada Nepenthes ovata bentuk kantung atas berbentuk seperti terompet. Ciri khas lain yang ditemukan adalah ditemukan dua bintik seperti mata pada kantung Nepenthes reinwardtiana. Bintik ini merupakan ciri yang tidak bisa dijumpai pada jenis lain.

\section{Bunga}

Pada Nepenthes bunga sering tidak diperhatikan karena tidak memiliki bentuk, ukuran dan warna yang menarik. Nepenthes sendiri merupakan tanaman berumah dua, sehingga penyebarannya kurang luas. Pada beberapa lokasi hanya ditemukan satu jenis bunga sehingga tidak bisa terjadi penyerbukan. selain dari generatif, bisa juga secara vegetatif. Individu baru bisanya dihasilkan dari tunas yang tumbuh dari nodus-nodus batang yang sudah tua, selain itu juga bisa dilakukan penyetekan.

\section{Jenis-Jenis Nepenthes yang Ditemukan} di Kecamatan Sipirok

1. Nepenthes eustachya Miq.

Memanjat, panjang tanaman 3-5 m. Batang: diameter 0,5-0,8 cm, bulat, ungu kehitaman; internodus 5-12 cm. Daun: panjang $10-20 \mathrm{~cm}$, lebar $4-5 \mathrm{~cm}$, lanset; tangkai daun 4-6 cm, bersayap, melingkar pada setengah batang, ungu kehitaman; ujung daun runcing, dasar daun runcing, tepi daun rata; ibu tulang daun jelas, 2-4 vena membujur; panjang sulur $12-15 \mathrm{~cm}$. Kantung bawah: tinggi 10-15 cm, lebar 3-4 $\mathrm{cm}$, bentuk seperti kendi berpinggang dengan bagian mulut yang melebar; lebar sayap $0,1-0,2 \mathrm{~cm}$, panjang filamen $0,1 \mathrm{~cm}$; 
Nurmaini Ginting, Keanekaragaman Nepenthes di Kecamatan Sipirok

mulut kantung orbikular; lebar bibir panjang perbungaan $15-20 \mathrm{~cm}$, anak kantung 0,5 cm, warna bervariasi; gigi tangkai bunga tunggal, tidak memiliki tidak jelas; penutup kantung orbikular, brakteola.

tepi rata; panjang taji $0,3-0,5 \mathrm{~cm}$, taji bercabang. Kantung atas: tinggi $15-20 \mathrm{~cm}$, lebar 4-5 cm, bentuk kendi berpinggang, bagian atas berbentuk silindris dengan bagian mulut melebar; tidak memiliki sayap; lebar bibir kantung 0,5-0,8 cm, warna bercorak, tepi bergelombang; panjang taji 0,5-1 cm. Perbungaan jantan: panjang tangkai $15-25 \mathrm{~cm}$, panjang perbungaan $30-40 \mathrm{~cm}$, anak tangkai bunga tunggal, tidak memiliki brakteola.

\section{Nepenthes gracilis Korth.}

Memanjat, panjang batang 4-5 m. Batang: diameter 0,3-0,5 cm, silindrisbersegi; Internodus 6-8 cm. Daun: panjang 13-15 cm, lebar 3-3,5 cm, bentuk lanset, ujung runcing, dasar daun runcing, tepi daun rata; ibu tulang daun jelas; terdapat 3-4 vena membujur; panjang sulur 7-15 cm. Kantong bawah: tinggi 5-7 cm, lebar 2$3 \mathrm{~cm}$, bentuk kendi; lebar sayap 2-3 cm, panjang filamen 0,1-0,15 cm; lebar bibir peristom 0,1-0,15 cm; gigi peristom tidak jelas; panjang 4-5 cm, lebar 2-3 cm, tutup berbentuk jantung; panjang taji 3-5 cm, tunggal. Kantong atas: tinggi 8-12, lebar 3$4 \mathrm{~cm}$, bentuk kendi; tutup kantung jantung, lebar bibir kantung 0,1-0,15 cm; gigi tidak jelas; panjang taji $2-2,5 \mathrm{~cm}$, tunggal. Perbungaan: panjang tangkai $10-15 \mathrm{~cm}$,

\section{Nepenthes ovata Nerz \& Wistuba}

Teresterial, terkadang ditemukan juga berupa epifit, memanjat, tinggi tanaman 2-4 m. Batang: diameter 0,3-0,45 $\mathrm{cm}$, bulat; internodus 3-6 cm. Daun: panjangnya 5-10 cm, lebar 1,5-2,5 cm, bentuk sudip; ujung runcing, dasar daun runcing, memeluk $1 / 2-2 / 3$ batang, tepi daun berbulu halus, coklat; ibu tulang daun jelas, 3-4 vena membujur; panjang sulur 18-20 cm, berbulu halus, coklat. Kantung bawah: tinggi 15-19 cm, lebar 3-4 $\mathrm{cm}$, bentuk gelas tambun; mulut kantung bulat telur; panjang tutup kantung 3-5 cm, lebar 2-3,5 cm, bentuk jantung; panjang tonjolan 1-1,5 cm, tunggal, seperti kait; lebar bibir kantung 3,5-5 cm, bagian luar gelombang; panjang gigi pada bibir 0,2-0,3 $\mathrm{cm}$, panjang gigi pada leher 0,38-0,42 cm; panjang taji $1-1,5 \mathrm{~cm}$, bercabang. Kantung atas: tinggi $18-23 \mathrm{~cm}$, lebar 4-5 cm, bentuk terompet; mulut kantung bulat telur; lebar tutup kantung 4-4,5 cm, bentuk seperti jantung; lebar bibir kantung 3-4,5 cm, bagian luar bergelombang, warna bervariasi; panjang gigi pada bibir 0,3-0,4 $\mathrm{cm}$, panjang gigi pada leher 0,4-0,55 cm; panjang taji 0,5-1 cm, bercabang dua. Perbungaan jantan: panjangnya $15-20 \mathrm{~cm}$, panjang tangkai 10-14 cm, berbulu halus, 
coklat, anak tangkai bunga tunggal, panjang 10-14 cm, lebar 4-5 cm, bentuk memiliki brakteola.

\section{Nepenthes reinwardtiana Miq.}

Memanjat, tinggi tanaman 5-6 m. Batang: berdiameter $0,5-0,7 \mathrm{~cm}$, bersegi tiga; internodus 6-12 cm. Daun: panjang daun 10-15 cm, lebar 2-4 cm, berbentuk lanset; ibu tulang daun jelas; 2-4 vena membujur; ujung runcing, dasar daun runcing, tepi daun berbulu halus; panjang sulur 13-17 cm. Kantung bawah: tinggi 8,5-10 cm dan lebar 4-6 cm, berbentuk kendi; lebar sayap 0,4-0,5 cm, panjang filamen 0,1-0,2 cm; mulut kantung bulat telur hampir bulat; panjang tutup kantung 2-3 cm, lebar 2-2,5 cm bentuk bulat telur; lebar bibir kantung 0,3-0,5 cm; gigi tidak jelas; panjang taji $0,4-0,5 \mathrm{~cm}$, tunggal. Kantung atas: tinggi 10-18 cm, lebar 5-7 $\mathrm{cm}$, bentuk kendi berpinggang; mulut kantung berbentuk bulat telur; panjang tutup kantung 2,5-3,5, lebar 2-2,5, bulat telur terbalik; terdapat dua spot seperti mata pada bagian dalam dekat leher kantung; lebar bibir kantung 0,2-0,3 cm; gigi tidak jelas; panjang taji 0,1-0,2 cm, tunggal. Perbungaan: tidak ditemukan.

\section{Nepenthes rhombicaulis Sh. Kurata}

Teresterial, terkadang epifit; memanjat, tinggi tanaman 2-5 m. Batang: diameter 0,43-0,5 cm, bersegi tiga, berbulu halus, coklat; internodus, 2,3-7 cm. Daun:

sudip; ujung runcing, dasar daun runcing, tepi daun berbulu halus, coklat; ibu tulang daun jelas; 2-3 vena yang membujur; panjang sulur $12-20 \mathrm{~cm}$, berbulu halus, jarang, coklat. Kantung bawah: tinggi 9-11 cm, lebar 2-3 cm bentuk kendi; lebar sayap 0,5-0,7 cm, panjang filamen 0,4-0,6 cm; mulut kantung bulat telur; lebar tutup kantung 2-2,8 cm, panjang 2-3 cm, bentuk bulat telur terbalik; lebar bibir kantung 1$1,3 \mathrm{~cm}$; panjang gigi pada bibir $0,1-0,2 \mathrm{~cm}$, panjang gigi pada leher 0,2-0,3 cm; panjang taji 0,3-0,5 cm, tunggal. Kantung atas: tinggi $10-13 \mathrm{~cm}$, lebar $2-3 \mathrm{~cm}$, bentuk kendi berpinggang; mulut kantung bulat telur; lebar tutup kantung 2-3 cm, panjang 3-3,5cm; lebar bibir kantung 1-1,5 cm; panjang gigi pada bibir 0,1-0,15 cm, panjang gigi pada leher 0,1-0,2 cm; panjang taji 0,4-0,6 cm, tunggal. Perbungaan: Panjang 25-32 cm, panjang tangkai 10-13 cm; berbulu halus, coklat, anak tangkai bunga tunggal dan bercabang dua, tidak memiliki brakteola.

\section{Nepenthes tobaica Danser}

Memanjat, tinggi tanaman 4-7 $\mathrm{m}$. Batang: diameter 0,3-0,5 cm, bulat; internodus15-20 cm. Daun: panjang 7-10 $\mathrm{cm}$, lebar 1,5-2 cm, bentuk lanset; ujung daun runcing, dasar daun runcing, tepi daun rata; ibu tulang daun jelas; 1-3 vena yang membujur; panjang sulur 10-15 cm. 
Nurmaini Ginting, Keanekaragaman Nepenthes di Kecamatan Sipirok

kantung bawah: tinggi 5-10 cm, lebar 1-1,5 bulat telur terbalik; lebar bibir kantung $\mathrm{cm}$, bentuk kendi; lebar sayap 0,2-0,3 cm, 0,1-0,2 cm; gigi tidak jelas; panjang taji panjang filamen 0,2-0,3 cm; mulut kantung 0,2-0,3 cm, tunggal. Perbungaan: tidak bulat telur; lebar tutup kantung 1-1,5 cm, ditemukan.

panjang 1,5-2 cm, bulat telur terbalik; lebar peristom 0,1-0,2 cm; gigi tidak jelas; panjang taji 0,3-0,5 cm, tunggal. Kantung atas: tinggi 8-12 cm, lebar 1,5-1,8 cm, bentuk kendi; mulut kantung bulat telur; panjang tutup kantung 1,5-2,2 cm, lebar 11,5 cm, bulat telur terbalik; lebar bibir kantung 0,1-0,2 cm; gigi tidak jelas; panjang taji 0,1-0,2 cm, tunggal. Perbungaan jantan: panjang 15-20 cm, panjang tangkai $10-20 \mathrm{~cm}$; anak tangkai bunga tunggal, tanpa brakteola. Perbungaan betina: panjang 15-18 cm, panjang tangkai $12-15 \mathrm{~cm}$; anak tangkai bunga tunggal, tanpa brakteola.

\section{Nepenthes tobaica $\mathrm{x}$ Nepenthes} reinwardtiana

Memanjat, tinggi tanaman 2-7 m. Batang: diameter 0,3-0,5 cm, bulat; internodus 20-30 cm. Daun: panjang 12-15 $\mathrm{cm}$, lebar 2-4 cm, bentuk lanset; ujung daun runcing, dasar daun runcing, tepi daun rata; ibu tulang daun jelas; 2-3 vena yang membujur; panjang sulur 20-25 cm. kantung bawah: tidak ditemukan. Kantung atas: tinggi $15-20 \mathrm{~cm}$, lebar 1,5-1,8 cm, bentuk kendi; mulut kantung bulat telur, bercorak merah hati dan hijau; panjang tutup kantung 2-3 cm, lebar 1-1,5 cm,

\section{SIMPULAN}

Dari penelitian yang telah dilakukan diperoleh kesimpulan sebagai berikut:

Ditemukan 8 jenis Nepenthes dimana diantaranya terdapat 1 jenis silangan alami. Nepenthes reinwardtiana memiliki penyebaran yang paling luas. Ditemukan jenis $N$. eustachya yang mana jenis ini belum pernah dilaporkan ditemukan pada daerah dataran tinggi.

\section{DAFTAR PUSTAKA}

Cheek, M. \& M. Jebb. (2001). Nepenthaceae. Flora Malesiana. Series I - Seed Plants, Vol 15.

Clarke, C. (1997). Another Nice Trip to Sumatra. International Carnivourus Plant Society (ICPS). www.carnivorousplants.org. Diakses 16 Januari 2011. .(2001). Nepenthes of Sumatra and Peninsular Malaysia . Kota Kinabalu, Sabah, Malaysia: Natural Publication (Borneo).

Fatahul, Adi dan Teten, (2006). Kantong semar (Nepenthes spp. sp.) Di hutan sumatera, Tumbuhan unik yang semakin langka. (OnLine).http://www.dephut.go.id/files/Fatahu 1-Azwar.pdf. Diakses tanggal 11 Januari 2009.

Hernawati, \& P. Akhriadi. (2006). A Field Guide to The Nepenthes of Sumatra, Padang: PILINGO Movement, Nepenthes Team, BP Conservation Programme, Conservation International-Indonesia.

Ginting, Nurmaini and Lubis, Jalilah Azizah. (2017). Inventarisasi Nepenthes di Tapanuli Selatan. Journal BIOLINK (Jurnal Biologi Lingkungan, Industri, Kesehatan. Vol 3. No. 2. Pages : 186--196

Suprayandi, (2007). Nepenthes spp., Tumbuhan Penangkap Serangga. (On-Line). 
BioLink, Vol.5 (1) (2018): hal. 22-30

http://pesanantar.wordpress.com/2007/03/1

7/Nepenthes spp./. Diakses tanggal 11

Oktober 2009. 